\title{
Maternal age and maternal environment affect stress reactivity and measures of social behaviour in laying hens
}

Mariana R. L. V. Peixoto

University of Guelph

Leanne Cooley

L.H. Gray \& Son Limited

Tina M. Widowski ( $\square$ twidowsk@uoguelph.ca )

University of Guelph

\section{Research Article}

Keywords: maternal age, maternal environment, laying hens, social behavior

Posted Date: April 15th, 2021

DOI: https://doi.org/10.21203/rs.3.rs-420373/v1

License: (c) (1) This work is licensed under a Creative Commons Attribution 4.0 International License.

Read Full License

Version of Record: A version of this preprint was published at Scientific Reports on September 1st, 2021. See the published version at https://doi.org/10.1038/s41598-021-96323-6. 


\section{Abstract}

Maternal effects can shape the phenotypes of offspring, but the extent to which a layer breeder's experience can affect commercial laying hens remains unclear. We aimed to investigate the effects of maternal age and maternal environment on laying hens' behaviour and stress response. In our first experiment (E1), commercial hybrid hens were reared either in aviary or barren brooding cages, then housed in aviary, conventional cages or furnished (enriched) cages, thus forming different maternal housing treatments. Hens from each treatment were inseminated at three ages, and measures of response to manual restraint and social stress were assessed in offspring. In experiment 2 (E2), maternal age effects on offspring's stress response were further investigated using fertile eggs from commercial breeder flocks at three ages. In E1, maternal age affected struggling and corticosterone during manual restraint, feather pecking and pulling and comb wounds. Additionally, maternal rearing and housing in aviary systems showed positive effects on measures of behaviour and stress response in offspring. Effects of maternal age were not replicated in E2, possibly due to methodological differences or higher tolerance to maternal effects in commercial breeders. Overall, we recommend researchers start reporting parent stock's age to increase our understanding of the subject.

\section{Introduction}

Maternal experience can affect offspring phenotype through epigenetic changes during gametogenesis ${ }^{1-3}$ and by changes in egg composition during ovogenesis ${ }^{4-6}$. Within the latter, yolk hormones, specifically steroids, have been suggested to have a strong link with maternal effects, allowing for modifications that signalize changes in the external environment to the young ${ }^{4}$. These modifications could be adaptive if mother and offspring share similar environments; or detrimental if their environments differ ("environmental matching hypothesis") ${ }^{7-9}$.

In their lifetimes, layer breeders in commercial production can produce approximately 115 female offspring ${ }^{10}$, meaning that their experiences $\mathrm{c}$ Previous research has shown that hens subjected to a moderate heat challenge for five consecutive weeks laid eggs with higher concentrations of yolk steroid hormones (progesterone, testosterone and estradiol) and had lighter and calmer offspring than control ${ }^{11}$. In the Japanese quail, human behaviour during handling (predictable and gentle versus unpredictable and fast) also affected the concentration of progesterone and estradiol in yolk and on offspring social discrimination skills ${ }^{12}$. Likewise, Japanese quails subjected to stressful events, such as sudden movement or unpredictable noise, laid eggs with higher yolk testosterone and progesterone, and produced chicks more sensitive to social separation (i.e., vocalized more during emergence and open-field tests) ${ }^{13}$. Interestingly, stressful events applied onto five genetic lines of layer breeders decreased offspring's sensitivity to social isolation in only one line, suggesting that maternal effects are also dependent on genetics ${ }^{14}$. 
In face of the global transition from conventional cages to cage-free systems, it is important to investigate the direct and indirect outcomes (e.g., maternal effects) of different housing systems for parent stock on the development, behaviour, and welfare of laying hens. Layer breeder parent stock are traditionally reared in conventional cages until 16-18 weeks of age (woa) and then transferred to either large groups on litter or smaller groups in colony cages ${ }^{15}$. However, due to concerns for animal welfare, we predict that attempts to rear breeder flocks in aviaries will soon start to be discussed. Although there is a paucity of literature on the subject, a recent multifactorial analysis of laying production, production of hatching eggs, and number of waste eggs showed that breeders reared in aviary and transferred to litter had better results compared to cage-reared birds ${ }^{16}$. From studies in commercial hens, it is known that aviary rearing improves the use of space ${ }^{17}$ and reduces fearfulness ${ }^{18}$, stress response ${ }^{19}$ and the number of eggs laid on litter ${ }^{20}$ in comparison to rearing in conventional brooding cages. Stress experienced during early life (around and before puberty) can also affect behaviour and stress response of offspring ${ }^{21}$. Adult housing was also shown to affect behaviour and stress response, with hens reared in conventional cages and housed in furnished cages producing less corticosterone at 50 woa and showing more comfort behaviour (preening) than hens both reared and raised in conventional systems 22,23 . It is, thus, clear that the environment can cause short- and long-term effects not only on production and physical traits but also on the behaviour and stress response of laying hens. Therefore, investigating the link between maternal housing and offspring's phenotype is a promising field of study that deserves attention.

Another emerging topic is the effect of maternal age on offspring's behaviour. It is common knowledge among producers that each flock is behaviourally unique, even when they come from the same genetic strain and provided identical nutrition and housing. One possible explanation is related to the mother's age. Layer breeder flocks typically begin producing offspring at around 20 woa and remain in production until around 70 woa, reaching an optimized performance at approximately 44 woa $^{15,24}$. As a hen gets older, the size and quantity of solid content in her eggs naturally change ${ }^{25}$. Similarly, yolk testosterone concentration has been found to decrease both in layers ${ }^{26}$ and quails ${ }^{27,28}$, possibly affecting their offspring's phenotype. Although the literature on the subject is still growing, previous research has shown that older quails ( 37 versus 11 woa) had less emotional offspring when encountering a novel object and vocalized more in response to social isolation ${ }^{27}$. Interestingly, Cooley et al. ${ }^{29}$ found opposite results in layers, with a decrease in the vocalization pattern of chicks from hens at 68 woa compared to chicks of mothers who were 25 and 44 woa. Although further studies investigating possible pathways for these effects are still needed, the link between maternal age and offspring behaviour is unquestionably exciting and offers a new area to be explored.

To our knowledge, no research has yet investigated the combination of maternal age and maternal environment in laying hens. The current study - which is part of a more comprehensive research project on maternal effects ${ }^{14,26,29-32}$ - investigates how maternal age, maternal rearing experience and maternal adult housing system affect their offspring's behaviour and stress response. For this, we conducted two experiments. In the first (E1), two cohorts of Lohmann Selected Leghorn -Lite hens were reared and 
housed in five housing system combinations and were inseminated at three ages (25, 44 and 68 woa), producing six offspring flocks. Measurements of stress reactivity and injurious behaviour were assessed. In addition, since layer breeders seem to be more resilient to maternal effects than commercial layers 14,31 , and to test the replicability of any maternal age effects seen in E1, we conducted a second experiment (E2) in which hatching eggs from layer breeders at three age groups ("Young" (25-27 woa),

"Ideal" (42-46 woa) and "Old" (68-72 woa)) were obtained from various commercial flocks across Canada and the United States. Stress response was measured in offspring at 4 woa. We hypothesized that maternal effects related to age and environment would be found in E1 and predicted the replicability of maternal age effects in E2.

\section{Methods}

The birds used in this study were treated in accordance with the Canadian Council on Animal Care, and all procedures were approved by the University of Guelph Animal Care Committee (Animal Utilization Protocol \#1947).

\section{Experiment 1 (E1)}

\section{Parent stock}

In this experiment, 2 consecutive cohorts of 588 Lohmann Selected Leghorn Lite (LSL-Lite) pullets each, were obtained from a commercial hatchery at one day of age and transferred to the University of Guelph's Arkell Poultry Research Station. Immediately upon arrival, half of the pullets from each flock were housed in conventional brooding cages (CC) with wire floors, while the other half was assigned to a tiered pullet aviary (Av) system.

At 16 weeks of age, equal numbers of pullets from Av rearing were transferred to conventional cages (CC), furnished cages (FC) and aviary systems (Av). Pullets from CC rearing were transferred to CC or FC. See Supplementary Material for details on housing conditions.

Each rearing and housing combination was considered a treatment (Figure 1). Hens from each treatment $(n=96)$ were randomly selected and inseminated with pooled semen from a contemporary group of White Leghorn males at 3 ages: Young (25 weeks), Ideal (44 weeks) and Old (68 weeks). Eggs from each maternal age, treatment and flock were collected and stored at $4^{\circ} \mathrm{C}$ until incubation.

Figure 1. Experiment 1. The combination between maternal rearing and housing experiences formed five treatment groups: Trt1 (Av x Av), Trt2 (CC X CC), Trt3 (Av X CC), Trt4 (CC X FC), Trt5 (Av X FC).

Birds from all treatments were fed identical, standard commercial crumbled pellet diets appropriate for rearing and lay and followed the same vaccination program. During rearing, room temperature was slowly decreased from $35^{\circ} \mathrm{C}$ at day 1 to $21^{\circ} \mathrm{C}$ by week 5 , while lighting was decreased from $16 \mathrm{~L}: 8 \mathrm{D}$ at 20 
lux to 8L:16D (lights on at 6:00h) at 10 lux by 9 weeks. During the laying period, ambient temperatures were maintained at $21^{\circ} \mathrm{C}$ and lighting schedule was $14 \mathrm{~L}: 10 \mathrm{D}$ at 20 lux for hens in all treatments.

\section{Offspring Management and Data Collection}

Offspring were hatched at the University of Guelph's Arkell Poultry Research Station using commercial grade incubators and hatchers (Nature Form, Jacksonville, FL). Chicks were sexed and individually wingbanded at hatch. Each cohort had four replicates of progeny ( 7 males and 7 females/each; $N=1,680$ ) per treatment and maternal age. Replicates were identically reared to 15 weeks in 20 floor pens $\left(3.72 \mathrm{~m}^{2}\right)$ that had a perch (length: $155 \mathrm{~cm}$ ) and were bedded with litter. The test order for the procedures described below were balanced across treatment and time of day in order to minimize any effects of circadian rhythm on the results.

\section{Manual restraint test}

At 9 weeks of age, 2 males and 2 females from each treatment replicate $(N=480)$ were subjected to a manual restraint test ${ }^{33}$, which aimed to measure a bird's behavioural and physiological response to stress through the assessment of number of escape attempts and plasma corticosterone (CORT) concentration. All birds were individually tested in a quiet space adjacent to their home pens. For this, each tested bird was removed from its pen and placed on a table. The test started when the bird was put on its side while the test person simultaneously restrained its chest and legs using both hands. During a period of 5 minutes, each successful attempt to escape (i.e., struggle) was recorded. Whenever that happened, the bird was immediately repositioned, and the test continued. Immediately following restraint, a blood sample $(3 \mathrm{ml})$ was drawn from the wing vein for CORT analysis before the bird was returned to the pen. For details on plasma extraction and enzyme immunoassay, see Supplementary Material.

\section{Comb pecking wounds}

Combs were assessed for pecking wounds according to the Welfare Quality protocol ${ }^{34}$, using a score of 0 to 2 . In this score, 0 meant no evidence of pecking wounds, 1 meant less than 3 pecking wounds, and 2 meant 3 or more wounds. All birds $(N=1,680)$ were scored at 9,11 and 13 weeks of age by 2 trained observers blind to treatment.

\section{Social feather pecking test}

Social feather pecking tests have been traditionally used to measure predisposition for feather pecking in laying hens ${ }^{35-37}$. In our study, 4 groups of 5 unfamiliar pullets from different replicate pens of the same treatment were formed and placed in a novel and bright environment for 60 minutes $(N=600)$. Since we only had 4 replicates per treatment, each test group had 2 pullets from the same home pen and 1 pullet from each of 3 different pens. However, this was balanced across groups.

One day before testing at 14 woa, birds were spray painted on their backs with different colours in order to allow for individual identification on video analyses. On test day, the pullets were crated, moved to the 
test room and placed into an arena made of solid white panels with two doors located on opposite walls and black rubber mats on the floor. The arena was internally divided with two white panels, thus forming 4 equally sized areas (50 cm long $\times 50 \mathrm{~cm}$ wide $\times 200 \mathrm{~cm}$ high) that were simultaneously used during the test. This layout prevented groups from seeing each other but was not acoustically isolated. On top of each section of the arena, a bright LED lamp and a camcorder (Panasonic HC-V180K) were attached to the ceiling. The cameras faced the centre of the arena and provided a full aerial view of the space. Pullets were recorded for 60 minutes and were immediately returned to their home pen after testing.

Measurements of behaviour were analysed from the video recordings by two observers blinded to treatment using Pocket Observer software (Observer XT, Noldus Information Technology, Wageningen, The Netherlands). Behaviour measurements are described in Table 1.

Table 1. Social feather pecking test. Ethogram used for behaviour observations.

Behaviour Description

\begin{tabular}{ll}
\hline $\begin{array}{l}\text { Aggressive } \\
\text { Peck }\end{array}$ & $\begin{array}{l}\text { A determined downward pecking, usually at the head and neck followed by } \\
\text { full body movement of the recipient. Each peck is an event. }\end{array}$ \\
$\begin{array}{l}\text { Feather Pull } \\
\text { Gentle Peck }\end{array}$ & $\begin{array}{l}\text { Removal of a feather from another bird. Each pull is an event. } \\
\text { Gentle, individual nibbling action, usually at the tail/wing. Each peck is an } \\
\text { event. }\end{array}$ \\
Preening & $\begin{array}{l}\text { The stroking of feathers with beak. A self-action. Recorded as total } \\
\text { duration. } \\
\text { A forceful peck usually directed at the back of a recipient not always } \\
\text { resulting in an aversive reaction from recipient. Each peck is an event. }\end{array}$ \\
\hline
\end{tabular}

\section{Experiment 2 (E2)}

\section{Parent stock}

In our second experiment, we aimed to further investigate the effects of maternal age in layer breeders obtained from commercial settings. For this, fertile eggs were acquired from 9, unique, commercial LSLLite White Leghorn layer breeder flocks located in Ontario, Quebec and New Brunswick, Canada and from Pennsylvania, USA. Breeder flocks were loose-reared and housed in floor barns. At the time of egg collection, 3 of the flocks were Young (25-27 woa), 3 were Ideal (42-46 woa) and 3 were Old (68-72 woa). All of the fertile eggs were shipped to University of Guelph's Arkell Poultry Research Station within the same week where egg storage, incubation and hatch occurred together, following the procedures previously described. From each parent flock, 2 replicates of progeny ( 7 males and 7 females; $n=28$ per flock) were identically reared to 41 days of age. Offspring were subjected to identical husbandry and housing as E1.

\section{Manual restraint test}


At 4 weeks of age, all birds ( $\mathrm{N}=252)$ were subjected to a manual restraint test. This time, the birds were physically restrained inside a cloth bag for 5 minutes prior to blood sample collection, following the methodology proposed by Wingfield ${ }^{38}$. Only measures of plasma CORT concentration were collected. All the birds were individually tested and immediately returned to their home pen.

\section{Data analyses}

The Glimmix procedure of SAS 9.4 (SAS Institute, Cary, NC) was used to perform statistical analyses. The basic statistical model for E1 included fixed effects of sex (when applicable), maternal treatment, maternal age and maternal treatment by age. Random effects included cohort, home-pen nested within room and person applying the test when applicable. Contrast comparisons tested effects of maternal rearing ( $\mathrm{Av}$ or $\mathrm{CC}$ ) and housing ( $\mathrm{Av}, \mathrm{CC}$ or $\mathrm{CF}$ ). Data from the manual restraint and social feather pecking tests were lognormally transformed. For comb pecking score, a multinomial distribution was used to test the effects of maternal age, treatment and sex, and contrasts and estimates were used to compare differences in the levels of fixed effects. Inter-observer reliability was calculated using Kendall's Tau-b coefficient, where a score of 1.0 is considered a perfect relationship, and a score of 0.7 is considered acceptable ${ }^{39}$. In E2, we used a generalized mixed model to test the effects of sex and maternal age on CORT concentration. Random effects included flock of origin and home-pen of the tested bird nested within room. Tests for normality included Shapiro-Wilk and Anderson Darling measurements in conjunction with visual plots for all analyses and statistical significance was defined as $p<0.05$ for both studies.

\section{Results}

\section{Manual restraint}

Table 2 summarizes the P-values for manual restraint for E1 and E2. In E1, plasma corticosterone (CORT) concentration $(P<0.001)$ and number of escape attempts $(P=0.035)$ increased as mothers aged (Figure 2). A treatment by maternal age interaction $(P=0.009$; Figure 3$)$ showed that within the Ideal flock age, the offspring of mothers reared in aviaries and housed in furnished cages (Trt 5) produced more CORT than those both reared and housed in aviaries (Trt 1).

Table 2. Manual restraint test. Effects of maternal age, treatment and treatment by maternal age on plasma corticosterone concentration and escape attempts, followed by contrast comparisons of maternal rearing and laying environments. 


\begin{tabular}{|c|c|c|c|c|}
\hline Manual Restraint & & & & E2 \\
\hline Effect & & $\begin{array}{c}\text { Plasma } \\
\text { Corticosterone }\end{array}$ & $\begin{array}{c}\text { Escape } \\
\text { attempts }\end{array}$ & $\begin{array}{c}\text { Plasma } \\
\text { Corticosterone }\end{array}$ \\
\hline Maternal age & & $<0.001$ & 0.035 & 0.882 \\
\hline Treatment & & 0.085 & 0.589 & - \\
\hline Sex & & 0.887 & $<0.001$ & $<0.001$ \\
\hline $\begin{array}{l}\text { Treatment x Maternal } \\
\text { age } \\
\text { Contrasts }\end{array}$ & & 0.009 & 0.764 & - \\
\hline Rearing housing & $\begin{array}{l}\text { Av vs } \\
\text { CC }\end{array}$ & 0.297 & 0.814 & - \\
\hline Laying housing & Av vs & 0.015 & 0.899 & - \\
\hline & Av vs & 0.007 & 0.509 & - \\
\hline & $\begin{array}{l}\text { CC vs } \\
\text { FC }\end{array}$ & 0.740 & 0.342 & - \\
\hline
\end{tabular}

Figure 2. Manual restraint test. (A) Average plasma corticosterone concentration ( $\mathrm{ng} / \mathrm{ml})$ and (B) average number of escape attemps displayed by maternal age. Statistical differences within tests are indicated by letters $(a-c)(P<0.05)$.

Figure 3. Manual restraint test. Effects of treatment and maternal age on plasma corticosterone concentration $(\mathrm{ng} / \mathrm{ml})$ displayed by maternal age. Statistical differences in plasma corticosterone concentration across treatments are indicated by letters $(a-d)(P<0.05)$.

Still in E1, no effects of sex were observed on plasma CORT $(P=0.887)$, but females struggled more (2.11 $\pm 0.2 \mathrm{ng} / \mathrm{ml})$ than males $(1.69 \pm 0.2 \mathrm{ng} / \mathrm{ml})$ during the test. Further pre-planned comparisons showed that the offspring of mothers housed in aviaries $(1.53 \pm 0.1 \mathrm{ng} / \mathrm{ml})$ during laying produced less CORT than the offspring of hens housed in either conventional $(1.78 \pm 0.2 \mathrm{ng} / \mathrm{ml})$ or furnished cages $(1.82 \pm 0.2 \mathrm{ng} / \mathrm{ml})$. No effects of treatment were found for escape attempts $(P=0.589)$.

E2 offspring showed no effects of maternal age on plasma CORT concentration ( $P=0.882)$. However, a sex effect was found $(P<0.001)$, with males $(2.56 \pm 0.1 \mathrm{ng} / \mathrm{ml})$ producing more CORT than females $(1.68$ $\pm 0.06 \mathrm{ng} / \mathrm{ml})$ in reponse to restraint.

\section{Comb score}

Comb score was affected by maternal age when offspring were 11 weeks of age $(P=0.001)$. Offspring from Young mothers had fewer non-injured combs (39\%) than those from Ideal (56\%) and Old (51\%) mothers (Supplementary Table S1). No effects of treatment were observed (Table 3), and males consistently displayed more injured combs than females.

Table 3. Comb score. Effects of sex, treatment, maternal age and treatment by maternal age on comb score, and contrast comparisons by rearing and laying environments. 


\begin{tabular}{lcccc}
\hline Comb Score & & \multicolumn{3}{c}{ P-values } \\
\cline { 3 - 5 } Effect & & 9 weeks & 11 weeks & 13 weeks \\
\hline Maternal Age & & 0.152 & $\mathbf{0 . 0 0 1}$ & 0.690 \\
Treatment & 0.280 & 0.552 & 0.557 \\
\hline Sex & & & & \\
Contrasts & & $\mathbf{0 0 1}$ & $\mathbf{0 . 0 0 1}$ & $<\mathbf{0 . 0 0 1}$ \\
\hline Rearing housing & Av vs CC & 0.567 & 0.925 & 0.890 \\
\hline Laying housing & Av vs CC & 0.679 & 0.597 & 0.678 \\
& Av vs FC & 0.235 & 0.420 & 0.153 \\
& CC vs FC & 0.153 & 0.092 & 0.210 \\
\hline
\end{tabular}

\section{Social feather pecking test}

Since not many hens performed either severe feather pecking or feather pull, we combined both measurements into one category (Severe Feather Peck \& Feather Pull). Maternal age affected the occurrence of severe pecking and feather pull $(P=0.016)$; offspring of Ideal mothers performed less pecking compared to offspring from Young and Old (Figure 4). Maternal treatment, however, did not affect any of the observed behaviours in the offspring (Table 4). Contrast comparisons showed that the offspring from hens reared in CC performed more preening (30.15 $\pm 6.8 \mathrm{~s})$ behaviour than Av (19.67 \pm $4.67 \mathrm{~s})$.

Table 4. Social feather pecking test. Effects of maternal age, treatment and treatment by maternal age on preening, aggressive peck, gentle peck and severe peck and feather pull, followed by contrast comparisons of rearing and laying environments.

\begin{tabular}{|c|c|c|c|c|c|}
\hline \multicolumn{2}{|c|}{ Induced Feather Pecking } & \multicolumn{4}{|c|}{ P-values } \\
\hline \multicolumn{2}{|c|}{ Effect } & Preening & $\begin{array}{l}\text { Aggressive } \\
\text { Peck }\end{array}$ & $\begin{array}{l}\text { Gentle } \\
\text { Peck }\end{array}$ & Severe Peck \& Feather Pull \\
\hline \multicolumn{2}{|l|}{ Maternal age } & 0.458 & 0.775 & 0.172 & 0.016 \\
\hline \multicolumn{2}{|c|}{ Treatment } & 0.145 & 0.662 & 0.863 & 0.899 \\
\hline \multicolumn{2}{|c|}{ Treatment x Maternal age } & 0.777 & 0.705 & 0.070 & 0.234 \\
\hline Rearing housing & Av vs CC & 0.016 & 0.438 & 0.309 & 0.466 \\
\hline \multirow[t]{3}{*}{ Laying housing } & Av vs CC & 0.785 & 0.345 & 0.697 & 0.642 \\
\hline & Av vs FC & 0.373 & 0.783 & 0.538 & 0.885 \\
\hline & CC vs FC & 0.434 & 0.425 & 0.797 & 0.697 \\
\hline
\end{tabular}

Figure 4. Social feather pecking test. Number of severe feather pecking and feather pull displayed by maternal age.

\section{Discussion}


Maternal age effects have been reported for a variety of response variables across several species. In invertebrates and mammals, they are frequently associated with increased mortality risk and infertility of offspring ${ }^{40}$. However, in avian species, inconsistency across results seems to be more frequent $27,29,40$, possibly due to natural changes in egg composition according to hen's age ${ }^{25}$ and environmental context ${ }^{4}$. Research in broiler breeders has linked maternal age to changes in yolk fatty acid profile ${ }^{41,42}$ and late embryonic mortality, hatchability, and body weight ${ }^{43}$. In addition, a previous report from our research group on the same birds used in E1 showed advanced maternal age was associated with less egg yolk testosterone and increased fearfulness in the offspring ${ }^{26}$, allowing for a potential relationship between the results reported here and maternal age effects due to changes in yolk testosterone concentration.

In E1, we found that older mothers had more reactive offspring during the restraint test. As mothers aged, their offspring had progressively higher concentrations of plasma CORT and struggled more. However, maternal effect on plasma CORT following restraint was not replicated in E2, possibly due to methodological differences, including the type of restraint and age at the time of testing. Since the hypothalamic-pituitary-adrenal (HPA)-axis is a set of components that matures over time, results are naturally expected to be age dependant ${ }^{44,45}$. Another point to be considered is the smaller experimental size in E2 compared to E1. Unfortunately, our study was performed during an Avian Influenza outbreak across North America that severely limited access to eggs from commercial breeder flocks. Lastly, the main goal of running two experiments was to access E1's replicability in commercial-like genetics. In commercial parent stock, female breeders are derived from different genetic lines than male breeders, and the commercial laying hen is the combination of both of their genetics. While we used commercial laying hens as a model for layer breeders in E1, we directly assessed the progeny of layer breeders in E2. Therefore, differences between experiments could be genetically driven, suggesting that layer breeders may be more resilient to maternal effects, as reported in previous studies ${ }^{14,32}$. Additionally, the housing and social environments of breeder flocks (usually comprising thousands of birds and allowing a natural mating system of hens and roosters ${ }^{15}$ ) can also affect the endocrine status of the hen ${ }^{46}$, thereby affecting the hormone content of the layer breeder's eggs 47 , and potentially masking maternal age effects.

Still in E1, we found effects of maternal age on injurious behaviour, including a higher occurrence of feather pulling and severe pecking in offspring of Young and Old mothers during the social feather pecking test; and worst comb condition at 11 woa in offspring from Young mothers. These tests reflect different aspects of social behaviour. The social feather pecking test was developed to identify individuals that are prone to feather pecking ${ }^{35-37}$, a multifactorial aberrant behaviour with many contributing factors, including genetics, early-life experience and various neurobiological pathways ${ }^{48}$. Differently, comb score reflects the occurrence of aggressive behaviour occurring in the birds' home environment. Although undesirable, aggressive pecking is a normal aspect of social development and functions to obtain resources, defend territory or establish social hierarchy ${ }^{49}$. Interestingly, the reported age for the establishment of social hierarchies in laying hens is around 9 to 12 woa ${ }^{50}$, coinciding with 
the maternal age effect observed at 11 woa in offspring from Young mothers. Thus, our results suggest that maternal age affects different aspects of social behaviour in laying hens, including propensity to feather pecking and aggression during establishment of a social hierarchy.

A maternal age by housing treatment interaction was only observed for one measure (plasma corticosterone), at one maternal age (Ideal), suggesting that the effects of early and current maternal housing experience might have a greater effect, or only are expressed, at certain maternal ages. Contrast comparisons showed that the offspring of mothers reared in Av displayed less preening behaviour during the social feather pecking test than CC; while the offspring of mothers housed in Av as adults had offspring that produced less corticosterone in response to manual restraint than CC and FC. Preening behaviour is displayed in several contexts: as grooming and comfort behaviour for maintenance of feather condition or as a displacement activity, related to situations of conflict, frustration and stress ${ }^{51}$. Therefore, results suggest that the offspring of Av-reared mothers were less emotional under a stressful situation, and the offspring of Av-housed mothers were physiologically less stressed by manual restraint.

Although there has been an increased scientific interest in the effects of maternal effects over the past decade, many questions remain unresolved, such as physiological pathways, susceptible periods, duration and consistency of effects ${ }^{52}$. Moreover, discrepancies across studies are often observed, as maternal effects are highly context dependent. Research suggests that rearing environment of laying hens can cause maternal effects through changes in DNA methylation profiles ${ }^{53}$; and stressors experienced during the laying period may be related to in ovo hormone-mediated maternal effects ${ }^{54}$. In view of this, we acknowledge the highly complex nature of this subject and encourage further research on both fundamental and applied levels.

Lastly, we did not observe any sex interaction with maternal age or maternal housing treatment combinations. This seemed rather surprising, as maternal effects are often sex-dependent ${ }^{52}$. However, we found sex differences in behavioural response to restraint ${ }^{55,56}$, comb score, which is an indirect measure of aggression 57,58 and stress response ${ }^{59,60}$. Sexually dimorphic behaviour is mainly related to the effects of gonadal hormones, androgens and estrogens, on the nervous system ${ }^{61}$. Individually and combined, these hormones can organize the neuronal circuitry involved in behavioural functions, including the serotonergic system ${ }^{62,63}$, responsible for traits of fear ${ }^{64}$, anxiety ${ }^{65}$, stress response ${ }^{66}$ and aggression ${ }^{67}$.

In conclusion, our study indicates that maternal age and maternal environment can affect offspring's behaviour and physiology when commercial hens are used as model for breeding chickens. Maternal age was shown to increase both the endocrine and behavioural response of the offspring to manual restraint, and to affect different aspects of injurious social behaviour such as comb wounds, which may be linked to the establishment of a social hierarchy, and susceptibility to feather pecking. Both maternal rearing and housing systems affected the offspring, but in different ways and possibly through different mechanisms. The offspring of mothers reared in Av were less emotional as indicated by less 
displacement preening in the social feather pecking test, whereas the chicks of mothers housed in aviaries at the time of fertilization had a lower stress response.

In light of our findings, we highlight the importance of maternal age and maternal environment on the behaviour and physiology of laying hens. In addition, we strongly recommend researchers to start reporting the age and housing condition of their birds' parent stock even if not their main focus of research. By doing this, they can provide data for future studies (e.g., meta-analysis) that will further clarify the extent of maternal effects. Likewise, we encourage farmers to note their flock's parents' age to identify possible behaviour patterns and eventually anticipate productive issues.

\section{Declarations}

\section{Data availability}

The data that support the findings of this study are available from the corresponding author upon reasonable request.

\section{Acknowledgements}

This research was funded by the 2013-2018 Poultry Science Cluster II which was supported by Agriculture and Agri-Food Canada and the Canadian Poultry Research Council, Egg Farmers of Canada and the Ontario Ministry of Agriculture and Rural Affairs (OMAFRA). We thank the personnel at the University of Guelph's Arkell Poultry Research Station for the technical assistance and maintenance of the birds. We also thanks Dr. Alexandra Harlander and Dr. Bas Rodenburg for suggestions during the development of this study.

\section{Author information}

\section{Affiliation}

Department of Animal Biosciences, University of Guelph, Guelph, Ontario, Canada

Mariana Roedel Lopez Vieira Peixoto \& Tina Widowski

L.H. Gray \& Son Limited, Strathroy, ON, Canada

Leanne Cooley

\section{Contributions}

T.W and L.C. conceived and designed the experiment. L.C. performed the experiment. M.P. assisted with data collection. M.P. and T.W. wrote the main manuscript. All authors reviewed and approved the final manuscript.

\section{Correspondence}


Correspondence to Tina Widowski (twidowsk@uoguelph.ca)

\section{Additional information}

\section{Competing interests statement}

The authors declare no competing interests.

\section{References}

1. Cao-Lei, L. et al. Prenatal stress and epigenetics. Neurosci. Biobehav. Rev. (2016). doi:10.1016/j.neubiorev.2017.05.016

2. Frésard, L. et al. Epigenetics and phenotypic variability: Some interesting insights from birds. Genetics Selection Evolution (2013). doi:10.1186/1297-9686-45-16

3. Sepers, B. et al. Avian ecological epigenetics: pitfalls and promises. J. Ornithol. 160, 1183-1203 (2019).

4. Groothuis, T. G. G., Hsu, B. Y., Kumar, N. \& Tschirren, B. Revisiting mechanisms and functions of prenatal hormone-mediated maternal effects using avian species as a model. Philos. Trans. R. Soc. B Biol. Sci. 374, (2019).

5. Groothuis, T. G. G. \& Schwabl, H. Hormone-mediated maternal effects in birds: Mechanisms matter but what do we know of them? Philos. Trans. R. Soc. B Biol. Sci. 363, 1647-1661 (2008).

6. Ruuskanen, S. \& Hsu, B.-Y. Maternal Thyroid Hormones: An Unexplored Mechanism Underlying Maternal Effects in an Ecological Framework. Physiol. Biochem. Zool. 91, 904-916 (2018).

7. Sheriff, M. J. \& Love, O. P. Determining the adaptive potential of maternal stress. Ecol. Lett. 16, 271280 (2013).

8. Gluckman, P. D. \& Hanson, M. A. The developmental origins of the metabolic syndrome. Trends in Endocrinology and Metabolism 15, 183-187 (2004).

9. Bateson, P., Gluckman, P. \& Hanson, M. The biology of developmental plasticity and the Predictive Adaptive Response hypothesis. J. Physiol. 592, 2357-2368 (2014).

10. Hy-Line International. Management Guide - HyLine Brown Parent Stock. 44 (2016). Available at: https://www.hyline.com/userdocs/pages/BRN_PS_ENG.pdf. (Accessed: 13th October 2019)

11. Bertin, A. et al. Moderate Heat Challenge Increased Yolk Steroid Hormones and Shaped Offspring Growth and Behavior in Chickens. PLoS One 8, e57670 (2013).

12. Bertin, A. et al. Human behaviour at the origin of maternal effects on offspring behaviour in laying hens (Gallus gallus domesticus). Physiol. Behav. 201, 175-183 (2019).

13. Guibert, F. et al. Trans-generational effects of prenatal stress in quail. Proc. R. Soc. B Biol. Sci. 280, 20122368 (2013).

14. Peixoto, M. R. L. V., Karrow, N. A., Newman, A. \& Widowski, T. M. Effects of Maternal Stress on Measures of Anxiety and Fearfulness in Different Strains of Laying Hens. Front. Vet. Sci. 7, (2020). 
15. Hy-Line International. Hy-Line Parent Stock Management Guide. 28

16. Damaziak, K., Musielak, M., Musielak, C., Riedel, J. \& Gozdowski, D. Reproductive performance and quality of offsprings of parent stock of layer hens after rearing in open and closed aviary system. Poult. Sci. 100, 1120-1131 (2021).

17. Tahamtani, F. M., Nordgreen, J., Nordquist, R. E. \& Janczak, A. M. Early life in a barren environment adversely affects spatial cognition in laying hens (Gallus gallus domesticus). Front. Vet. Sci. 2, 1-12 (2015).

18. Brantsæter, M. et al. Exposure to increased environmental complexity during rearing reduces fearfulness and increases use of three-dimensional space in laying hens (Gallus gallus domesticus). Front. Vet. Sci. 3, 1-10 (2016).

19. Campbell, D. L. M., Hinch, G. N., Downing, J. A. \& Lee, C. Early enrichment in free-range laying hens: effects on ranging behaviour, welfare and response to stressors. Animal 12, 575-584 (2018).

20. Janczak, A. M. \& Riber, A. B. Review of rearing-related factors affecting the welfare of laying hens. Poult. Sci. 94, 1454-1469 (2015).

21. Ericsson, M. et al. Long-term and transgenerational effects of stress experienced during different life phases in chickens (Gallus gallus). PLoS One 11, (2016).

22. Pohle, K. \& Cheng, H.-W. Comparative effects of furnished and battery cages on egg production and physiological parameters in White Leghorn hens. Poult. Sci. 88, 2042-2051 (2009).

23. Pohle, K. \& Cheng, H.-W. Furnished cage system and hen well-being: Comparative effects of furnished cages and battery cages on behavioral exhibitions in White Leghorn chickens. Poult. Sci.

88, 1559-1564 (2009).

24. Nwogu, E. C. \& Acha, C. K. Age of birds at optimal production of eggs: A polynomial regression analysis. Pakistan J. Stat. Oper. Res. (2014). doi:10.18187/pjsor.v10i2.469

25. Ahn, D. U., Kim, S. M. \& Shu, H. Effect of Egg Size and Strain and Age of Hens on the Solids Content of Chicken Eggs. Poult. Sci. (1997). doi:10.1093/ps/76.6.914

26. Cooley, L. \& Widowski, T. M. The effect of maternal age, rearing and housing environments on yolk testosterone and fear-related behavior of leghorn chicks. in Poultry Science 97 (E-Supplement 1) 4546 (2018).

27. Guibert, F. et al. Yolk testosterone levels and offspring phenotype correlate with parental age in a precocial bird. Physiol. Behav. 105, 242-250 (2012).

28. Okuliarová, M., Škrobánek, P. \& Zeman, M. Variability of yolk testosterone concentrations during the reproductive cycle of Japanese quail. Comp. Biochem. Physiol. - A Mol. Integr. Physiol. (2009). doi:10.1016/j.cbpa.2009.08.012

29. Cooley, L., Hendriksen, S. \& Widowski, T. M. Maternal age affects leghorn chick response to the Anxiety Depression Model. in 50th International Congress of the ISAE 205 (2016).

30. Cooley, L. \& Widowski, T. M. The effect of maternal age, reating and housing environments on egg traits and growth of leghorn chicks. in XXV World's Poultry Congress 515 (2016). 
31. Peixoto, M. R. L. V., Karrow, N. A., Newman, A., Head, J. \& Widowski, T. M. Effects of acute stressors experienced by five strains of layer breeders on measures of stress and fear in their offspring. Physiol. Behav. 228, 113185 (2021).

32. Peixoto, M. R. L. V., Karrow, N. A. \& Widowski, T. M. Effects of prenatal stress and genetics on embryonic survival and offspring growth of laying hens. Poult. Sci. 99, 1618-1627 (2020).

33. Uitdehaag, K. A. et al. Effects of mixed housing of birds from two genetic lines of laying hens on open field and manual restraint responses. Behav. Processes 79, 13-18 (2008).

34. Algers, B. et al. Welfare Quality ® Assessment protocol for poultry. 111 (2009).

35. Rodenburg, T. B. \& Koene, P. Comparison of individual and social feather pecking tests in two lines of laying hens at ten different ages. Appl. Anim. Behav. Sci. (2003). doi:10.1016/S0168-1591(02)002757

36. Kjaer, J. B. \& Sørensen, P. Feather pecking behaviour in White Leghorns, a genetic study. Br. Poult. Sci. (1997). doi:10.1080/00071669708417999

37. Kjaer, J. B., Sorensen, P. \& Su, G. Divergent selection on feather pecking behaviour in laying hens (Gallus gallus domesticus). Appl. Anim. Behav. Sci. (2001). doi:10.1016/S0168-1591(00)00184-2

38. Wingfield, J. C., Vleck, C. M. \& Moore, M. C. Seasonal changes of the adrenocortical response to stress in birds of the Sonoran desert. J. Exp. Zool. 264, 419-428 (1992).

39. Arndt, S., Turvey, C. \& Andreasen, N. C. Correlating and predicting psychiatric symptom ratings: Spearman's v versus Kendall's tau correlation. J. Psychiatr. Res. 33, 97-104 (1999).

40. Ivimey-Cook, E. \& Moorad, J. The diversity of maternal-age effects upon pre-adult survival across animal species: Diversity of maternal-age effects. Proc. R. Soc. B Biol. Sci. (2020). doi:10.1098/rspb.2020.0972

41. Latour, M. A. et al. Broiler Breeder Age and Dietary Fat Influence the Yolk Fatty Acid Profiles of Fresh Eggs and Newly Hatched Chicks. Poult. Sci. (1998). doi:10.1093/ps/77.1.47

42. Burnham, M. R. et al. Effects of incubator humidity and hen age on yolk composition in broiler hatching eggs from young breeders. Poult. Sci. (2001). doi:10.1093/ps/80.10.1444

43. Yilmaz-Dikmen, B. \& Sahan, U. The relationship among age, yolk fatty acids content, and incubation results of broiler breeders. Poult. Sci. 88, 185-190 (2009).

44. Ericsson, M. \& Jensen, P. Domestication and ontogeny effects on the stress response in young chickens (Gallus gallus). Sci. Rep. 6, 1-7 (2016).

45. Hazard, D., Couty, M., Faure, J. M. \& Guémené, D. Relationship between hypothalamic-pituitaryadrenal axis responsiveness and age, sexual maturity status, and sex in Japanese quail selected for long or short duration of tonic immobility. Poult. Sci. (2005). doi:10.1093/ps/84.12.1913

46. Craig, J. V., Craig, J. A. \& Vargas Vargas, J. Corticosteroids and other indicators of hens' well-being in four laying-house environments. Poult. Sci. (1986). doi:10.3382/ps.0650856

47. Groothuis, T. G. G., Müller, W., Von Engelhardt, N., Carere, C. \& Eising, C. Maternal hormones as a tool to adjust offspring phenotype in avian species. Neurosci. Biobehav. Rev. 29, 329-352 (2005). 
48. van Staaveren, N. \& Harlander, A. Cause and prevention of injurious pecking in chickens. in Understanding the behaviour and improving the welfare of chickens (ed. Nicol, C.) 509-566 (Burleigh Dodds Science Publishing, 2020). doi:10.19103/as.2020.0078.15

49. Savory, C. J. Feather pecking and cannibalism. Worlds. Poult. Sci. J. 51, 215-219 (1995).

50. Estevez, I., Keeling, L. J. \& Newberry, R. C. Decreasing aggression with increasing group size in young domestic fowl. Appl. Anim. Behav. Sci. (2003). doi:10.1016/j.applanim.2003.08.006

51. Zimmerman, P. H., Buijs, S. A. F., Bolhuis, J. E. \& Keeling, L. J. Behaviour of domestic fowl in anticipation of positive and negative stimuli. Anim. Behav. 81, 569-577 (2011).

52. Henriksen, R., Rettenbacher, S. \& Groothuis, T. G. G. Prenatal stress in birds: Pathways, effects, function and perspectives. Neurosci. Biobehav. Rev. 35, 1484-1501 (2011).

53. Pértille, F. et al. DNA methylation profiles in red blood cells of adult hens correlate with their rearing conditions. J. Exp. Biol. (2017). doi:10.1242/jeb.157891

54. Henriksen, R., Groothuis, T. G. \& Rettenbacher, S. Elevated Plasma Corticosterone Decreases Yolk Testosterone and Progesterone in Chickens: Linking Maternal Stress and Hormone-Mediated Maternal Effects. PLoS One 6, e23824 (2011).

55. Jones, R. B. Sex and strain differences in the open-field responses of the domestic chick. Appl. Anim. Ethol. 3, 255-261 (1977).

56. Jones, R. B. \& Faure, J. M. Sex and strain comparisons of tonic immobility ('Righting time') in the domestic fowl and the effects of various methods of induction. Behav. Processes 6, 47-55 (1981).

57. Vallortigara, G. Affiliation and aggression as related to gender in domestic chicks (Gallus gallus). J. Comp. Psychol. (1992). doi:10.1037/0735-7036.106.1.53

58. Millman, S. T., Duncan, I. J. H. \& Widowski, T. M. Male broiler breeder fowl display high levels of aggression toward females. Poult. Sci. (2000). doi:10.1093/ps/79.9.1233

59. Handa, R. J. \& Weiser, M. J. Gonadal steroid hormones and the hypothalamo-pituitary-adrenal axis. Front. Neuroendocrinol. 35, 197-220 (2014).

60. Kudielka, B. M. \& Kirschbaum, C. Sex differences in HPA axis responses to stress: A review. Biological Psychology (2005). doi:10.1016/j.biopsycho.2004.11.009

61. Palanza, P. Animal models of anxiety and depression: How are females different? Neurosci. Biobehav. Rev. 25, 219-233 (2001).

62. Carlsson, M. \& Carlsson, A. A regional study of sex differences in rat brain serotonin. Prog. Neuropsychopharmacol. Biol. Psychiatry 12, 53-61 (1988).

63. Sturkie, P. D., Woods, J. J. \& Meyer, D. Serotonin Levels in Blood, Heart, and Spleen of Chickens, Ducks, and Pigeons. Proc. Soc. Exp. Biol. Med. (1972). doi:10.3181/00379727-139-36144

64. Phi Van, V. D., Krause, E. T. \& Phi-Van, L. Modulation of fear and arousal behavior by serotonin transporter (5-HTT) genotypes in newly hatched chickens. Front. Behav. Neurosci. (2018). doi:10.3389/fnbeh.2018.00284 
65. Heisler, L. K., Zhou, L., Bajwa, P., Hsu, J. \& Tecott, L. H. Serotonin 5-HT2C receptors regulate anxietylike behavior. Genes, Brain Behav. 6, 491-496 (2007).

66. Goel, N., Workman, J. L., Lee, T. T., Innala, L. \& Viau, V. Sex differences in the HPA axis. Compr. Physiol. (2014). doi:10.1002/cphy.c130054

67. Cheng, H. W. \& Muir, W. M. Mechanisms of aggression and production in chickens: Genetic variations in the functions of serotonin, catecholamine, and corticosterone. Worlds. Poult. Sci. J. (2007). doi:10.1017/S0043933907001432

\section{Figures}

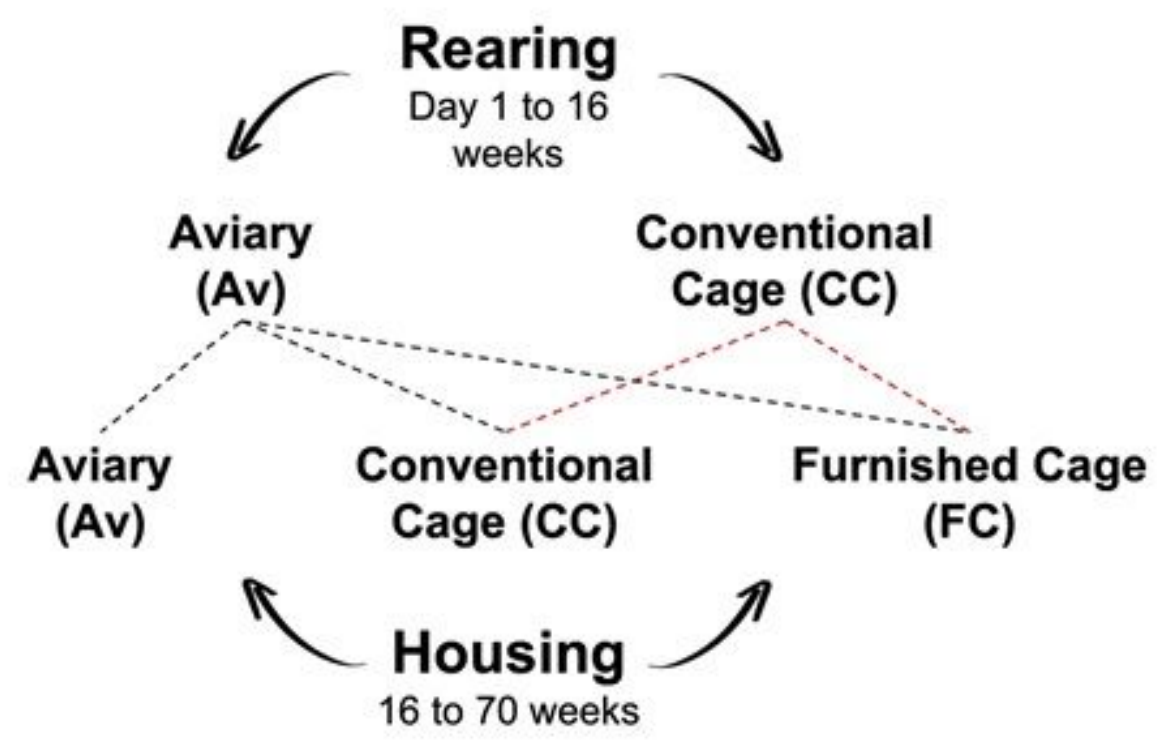

Figure 1

Experiment 1. The combination between maternal rearing and housing experiences formed five treatment groups: Trt1 (Av X Av), Trt2 (CC X CC), Trt3 (Av X CC), Trt4 (CC X FC), Trt5 (Av X FC).
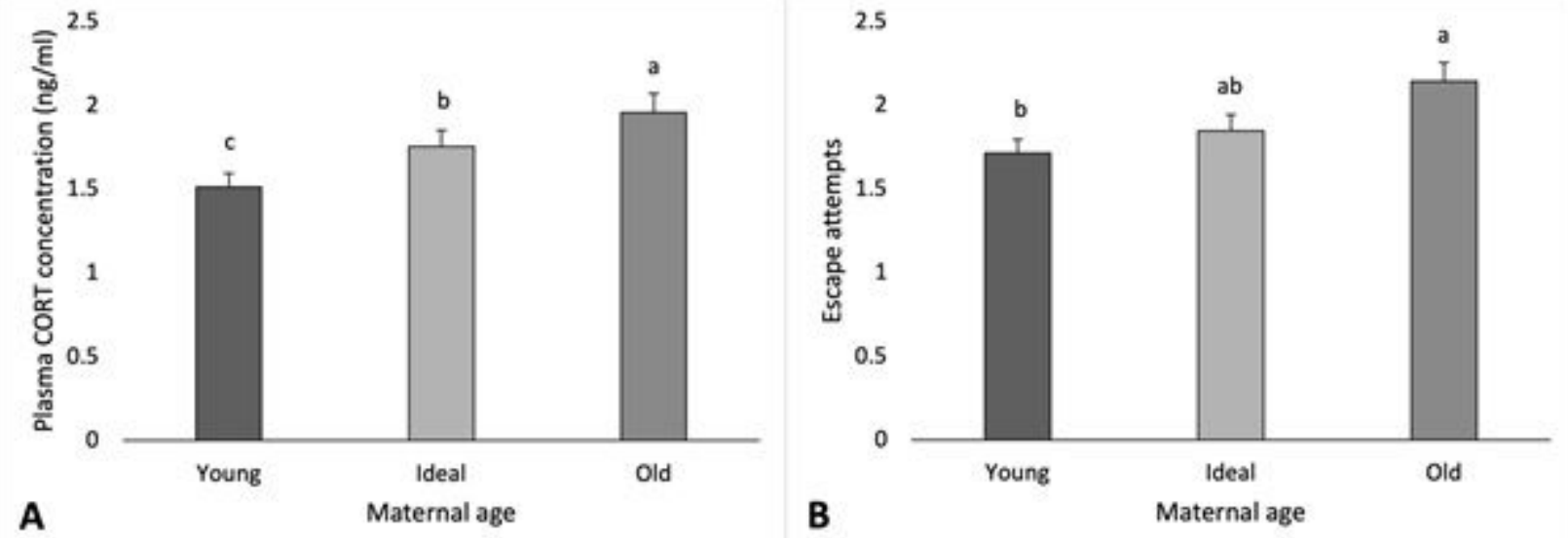

Figure 2 
Manual restraint test. (A) Average plasma corticosterone concentration $(\mathrm{ng} / \mathrm{ml})$ and $(B)$ average number of escape attemps displayed by maternal age. Statistical differences within tests are indicated by letters (a-c) $(\mathrm{P}<0.05)$.

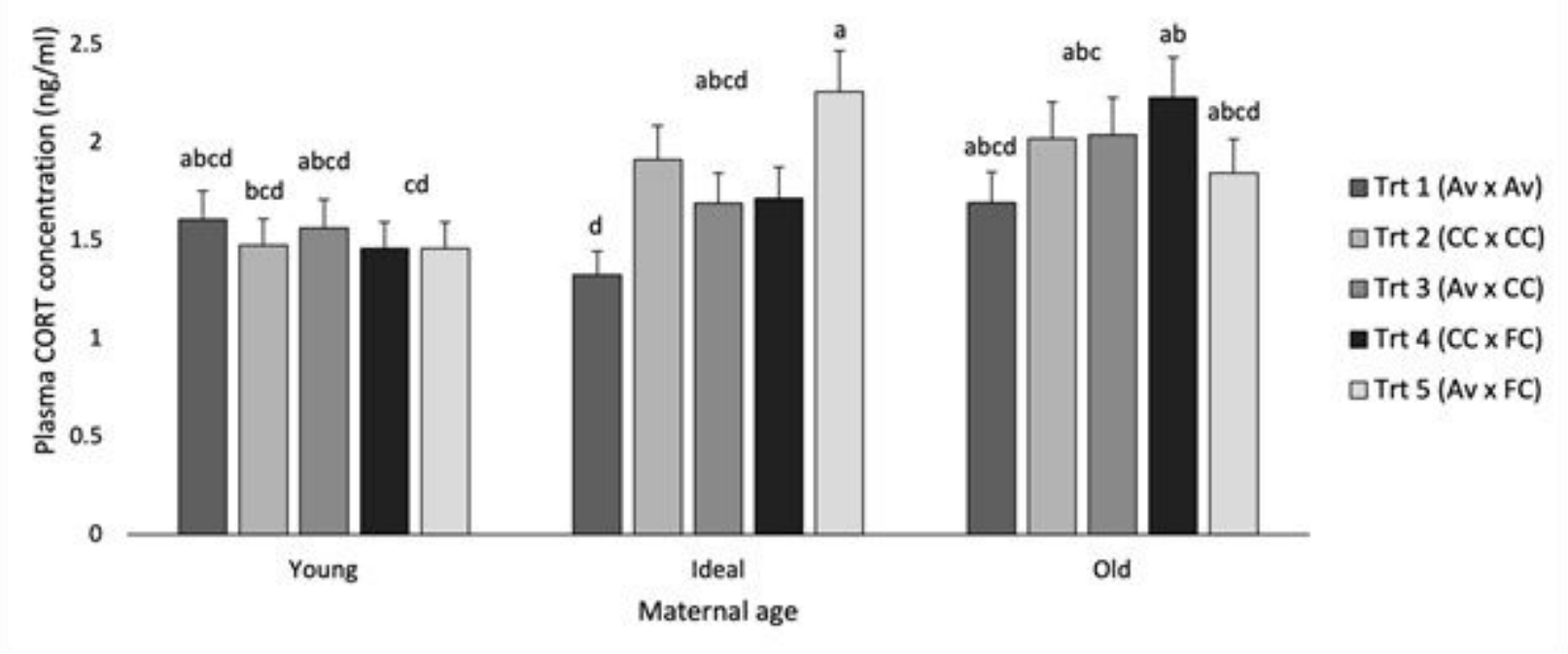

\section{Figure 3}

Manual restraint test. Effects of treatment and maternal age on plasma corticosterone concentration $(\mathrm{ng} / \mathrm{ml})$ displayed by maternal age. Statistical differences in plasma corticosterone concentration across treatments are indicated by letters $(a-d)(P<0.05)$.

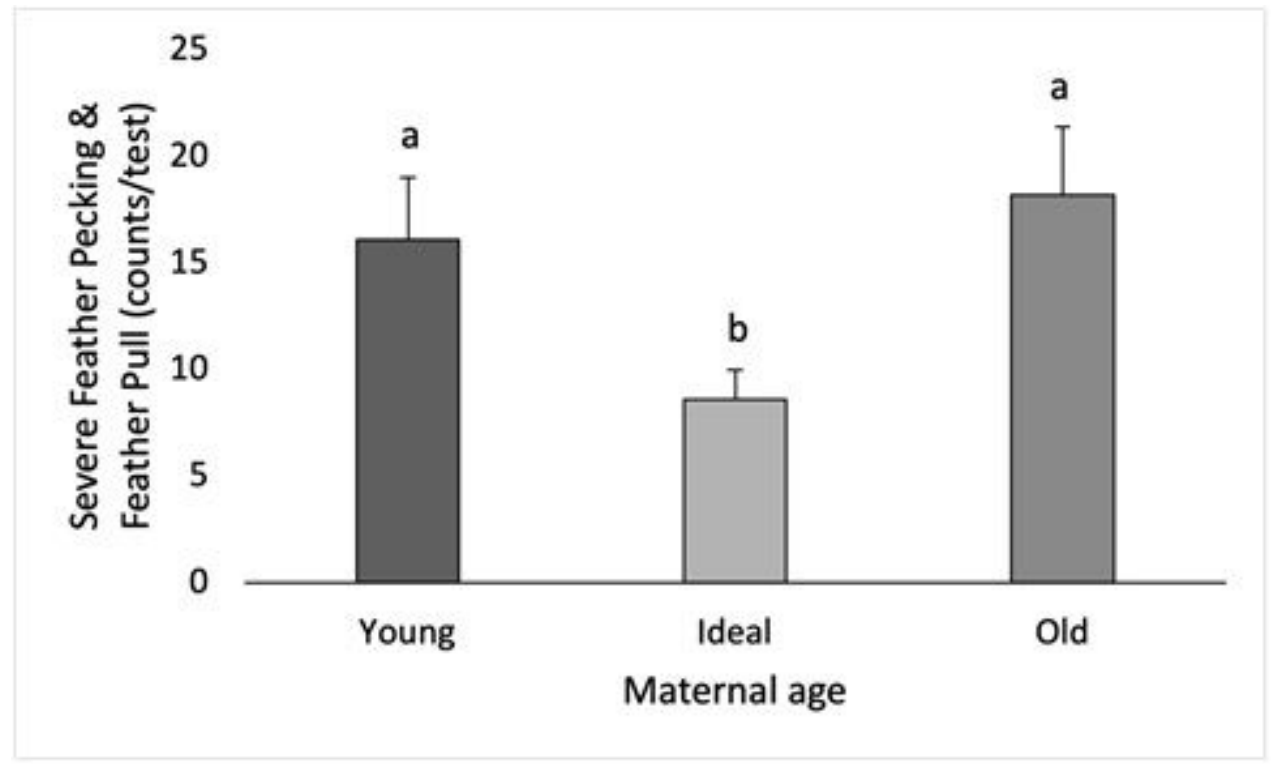

Figure 4

Social feather pecking test. Number of severe feather pecking and feather pull displayed by maternal age.

\section{Supplementary Files}


This is a list of supplementary files associated with this preprint. Click to download.

- SciReportsSupplementarymaterial.docx 